\title{
PERAN RUANG RELAKSASI PADA PERANCANGAN BERKONSEP KREATIF UNTUK PENINGKATAN KREATIVITAS KARYAWAN KANTOR 24SLIDES INDONESIA
}

\author{
Aurellia Cintana Satya Nagara ${ }^{1}$, Hana Kireina Widiyanti $^{2}$, Mellani Vionita ${ }^{3}$, \\ Rizquita Tsania ${ }^{4}$, Ira Audia Agustina ${ }^{5}$
}

\author{
Interior Design Department - School of Design Bina Nusantara University Jakarta \\ aurellia.nagara@binus.ac.id, hana.widiyanti@binus.ac.id, mellani.vionita@binus.ac.id,
} rizquita.tsania@binus.ac.id, ira.agustina@binus.edu

\begin{abstract}
If a creative industry office requires new creativity and innovation ideas, then a relaxation facility with some communicative games is recommended to stimulate the brain. Providing these facilities will restore workers' enthusiasm before taking a break or starting an activity. Lounge facilities or lounge rooms are also not provided that simple way. With an attractive interior design, it could be the other proponent as well as supporting housing from the office. Thus, the authors make a study research related to the design of a relaxation room that is suitable for the 24Slides office. The purpose of this research is to figure out the creativity and productivity enhancement of workers with the existence of a relaxation room, knowing the responses of workers, and designing concepts. Design Thinking is used as a method of this research, consisting of emphatize, define, ideate, prototype and test. Data collection was carried out by conducting interviews with 5 respondents and a field survey at the 24 Slides office. The data analysis carried out in the form of assessing existing analyzes, field surveys and interviews that had been obtained. The results of this study will be used as a reference to carry out the design of the relaxation room (funspace) at the 24 Slides Indonesia office.
\end{abstract}

Keywords: Creative industry office, 24Slides Indonesia, creativity, relaxation space (funspace)

\begin{abstract}
Abstrak: Jika sebuah kantor industri kreatif membutuhkan kreativitas dan inovasi yang selalu baru, maka fasilitas relaksasi dengan beberapa permainan komunikatif yang dapat menstimulasi otak adalah hal yang direkomendasikan. Penyediaan fasilitas tersebut dinilai akan mengembalikan semangat pekerja disaat waktu istirahat atau sebelum memulai aktivitas. Fasilitas berupa ruang relaksasi atau fun space juga tidak serta merta disediakan begitu saja. Dengan desain interior yang menarik, maka akan menjadi penunjang selanjutnya sekaligus mendukung suasana dari sebuah kantor. Untuk itu, penulis membuat studi penelitian terkait implementasi desain ruang relaksasi yang cocok pada kantor 24Slides. Penelitian ini bertujuan untuk mengetahui peningkatan kreativitas dan produktivitas para pekerja dengan adanya ruang relaksasi, mengetahui tanggapan para pekerja, serta melakukan perancangan konsep. Metode penelitian yang digunakan berupa design thinking yang terdiri dari emphatisize, define, ideate, prototype dan test. Pengumpulan data dilakukan dengan cara melakukan wawancara pada 5 responden serta survei lapangan pada kantor 24Slides. Analisis data yang dilakukan berupa pengkajian analisa existing, survei lapangan serta wawancara yang sudah didapat. Hasil dari penelitian ini akan digunakan sebagai acuan untuk melaksanakan perancangan ruang relaksasi (fun space) pada kantor 24Slides Indonesia.
\end{abstract}

Kata kunci: Kantor industri kreatif, 24Slides Indonesia, kreativitas, ruang relaksasi (funspace).

Sebagai karyawan atau karyawati yang bekerja pada perusahaan dibidang industri kreatif dituntut untuk selalu dapat mengutarakan inovasi kreatif dalam bekerja dan mampu mengikuti perkembangan teknologi guna mencapai keunggulan

Received on : :09/07/2020

Revised on : 24/03/2021

Accepted on : 24/03/2021 kompetitif antar perusahaan. Chesbrough (2010) menyatakan bahwa inovasi adalah sesuatu hal yang sangat vital bagi kelangsungan bisnis, dan juga merupakan hal yang sulit dicapai. Salah satu aset utama industri kreatif dipertimbangkan oleh 
karyawan berkinerja tinggi, oleh karena itu perusahaan memberikan lebih banyak upaya dan dengan menggunakan strategi pengembangan sumber daya manusia yang berbeda, mereka mencoba untuk meningkatkan kemampuan dan kompetensi karyawan.

Dalam konteks industri jasa, kepuasan pelanggan biasanya tergantung pada kinerja karyawan. Oleh karena itu perusahaan memberikan lebih banyak fasilitas, pemberdayaan karyawan,untuk mendukung produktivitas kerja. Menurut (Eisenberger et al., 1986) berpendapat bahwa, jika organisasi menciptakan iklim kerja yang mendukung bagi karyawan mereka yang meningkatkan persepsi positif mereka tentang organisasi dan konsekuensi fisiologis, akibatnya yang mendorong perilaku timbal balik mereka ke arah meningkatkan kinerja pekerjaan mereka. Dalam konteks ini kesenangan di tempat kerja memainkan peran penting dengan bersosialisasi dengan rekan kerja, merayakannya di tempat kerja dan kebebasan pribadi untuk meningkatkan iklim kerja bahagia karyawan dan meningkatkan kinerja kerja mereka (Fluegge ER,2008).

Menurut (Patel, 2013) dalam lingkungan kerja yang penuh tekanan, kesenangan di tempat kerja yang sudah difasilitasi sangat penting untuk menghilangkan masalah dan kekhawatiran kehidupan kerja sehari-hari yang penuh tekanan. Suasana kantor yang menyenangkan memiliki peran penting untuk Produktivitas karyawan di tempat kerja. tempat kerja yang bahagia adalah tempat di mana karyawan yang bahagia adalah karyawan yang lebih loyal dan produktif. Tingkat absensi dan keterlambatan serendah karyawan menantikan untuk pergi bekerja. Kegembiraan adalah salah satu jenis obat, jika karyawan meminumnya, itu akan meningkatkan moral, kinerja, meningkatkan antusiasme karyawan, mengurangi keluhan akan kebosanan, dan yang paling penting yang membuat karyawan senang dan kehilangan waktu (Eisenberger et al., 1986) Kesenangan di tempat kerja memberi berbagai manfaat organisasi dan hasil kerja yang maksimal. Diantaranya meliputi fleksibilitas, keunggulan kompetitif dan peningkatan motivasi (Fleming, 2009), (Peters, 1992), layanan pelanggan yang baik, inovasi, pemberdayaan, kreativitas (Barsoux, 1993), (Bolman, 2000), (Deal, 1999), (Patel, 2012) dan produktivitas (Pinault, 2004).

Oleh karena itu, pada perancangan kali ini melalui objek penelitian Kantor 24 Slides, kami akan menambahkan fasilitas ruang relaksasi berupa perpustakaan dan game room guna meningkatkan produktivitas dan kreativitas karyawan 24 Slides yang bergerak pada industri kreatif. Pemilik kantor 24 Slides sangat memperhatikan fasilitas dan kesenangan karyawan karena pada perusahaan tersebut karyawan adalah aset utama.

Pada area relaksasi kami ingin membangun suasana yang fun dan dapat melepaskan rasa penat karyawan. Kami menambahkan berbagai macam permainan tradisional seperti board game agar karyawan tidak bosan melihat layar komputer. Kami juga menambahkan android tv untuk bermain playstation dan hammock agar karyawan dapat bersantai. Dengan perancangan ini kami berharap karyawan akan meningkatkan produktivitas karyawan dan juga dapat memenuhi kesenangan batin karyawan 24 Slides.

Neufert (2012) menjelaskan pada buku Architect Data bahwa karyawan menjadi semakin penting dalam organisasi pekerjaan kantor. Faktor-faktor seperti citra perusahaan (identitas perusahaan), desain area untuk istirahat dan relaksasi maupun konfigurasi individual tempat kerja semuanya dimaksudkan untuk meningkatkan kinerja karyawan (Neufert, 2012).

Kreativitas adalah kemampuan untuk menghasilkan sesuatu yang baru. Hal ini berarti produksi oleh satu atau lebih orang ide dan penemuan yang bersifat pribadi, asli dan bermakna (Howkins, 2001).

Dilansir dari Dinas Perindustrian dan Perdagangan Provinsi Jawa Timur (Suhail, 2016), terdapat beberapa subsektor industri kreatif, salah satunya adalah desain, yang mencakup kegiatan kreatif yang terkait dengan kreasi desain grafis, desain interior, desain produk, desain industri, konsultasi identitas 
perusahaan dan jasa riset pemasaran serta produksi kemasan dan jasa pengepakan. Menteri Pariwisata dan Ekonomi Kreatif/Kepala Badan Pariwisata dan Ekonomi Kreatif, Wishnutama Kusubandio (Fitriani, 2020), mengatakan bahwa sektor ekonomi kreatif mempunyai potensi besar menjadi tulang punggung perekonomian Indonesia ke depan, sehingga dibutuhkan peran semua pihak dalam menciptakan ekosistem yang menunjang. Beliau juga mengungkapkan bahwa Indonesia menjadi salah satu negara di dunia yang diperhitungkan dalam bisnis ekonomi kreatif di tingkat dunia. Untuk itu, Indonesia harus mengambil peran, terlebih PBB telah menyetujui tahun 2021 sebagai "International Year of Creative Economy for Sustainable Development" di mana Indonesia menjadi inisiator dalam resolusi tersebut.

Dikutip dari Design Desk (Design Desk, 2020), ada beberapa manfaat jika perusahaan menerapkan ruang relaksasi atau playzone di lingkungan kantor, yakni dapat meningkatkan produktivitas, kepuasan kerja, inovasi dan kreativitas, moral, dan efisiensi dalam bekerja. Tak hanya itu saja, ruang relaksasi ini dapat menurunkan ketidakhadiran karyawan, pergantian karyawan, stress, dan frustasi.

\section{METODE PENELITIAN}

Metode dalam perancangan desain yang saat ini sangat populer dan terkini adalah Design Thinking. Metode ini berfokus pada pengguna atau user di mana perancang dapat memahami permasalahan pada interior kantor 24Slides yang diharapkan dapat mengatasi masalah kompleks pada sebuah perancangan interior. (Ali, 2017).

\section{Emphatize}

Pada tahap 1 ini, perancang mengkaji latar belakang dari perusahaan 24Slides yang kemudian ditemukannya visi dan misi dari perusahaan tersebut. Tim perancang melakukan survei lapangan dengan menganalisa bagaimana aksesibilitas, sirkulasi, permasalahan dan kondisi bangunan kantor 24Slides. Peneliti juga melakukan wawancara pada karyawan kantor mengenai aktivitas, pengisian ruang, karakter ruang, dan kebutuhan desain di masa yang akan datang.

\section{Define}

Hasil Analisa survei lapangan dan wawancara yang didapat kemudian dikaji. Dari beberapa permasalahan yang didapat, perancang melakukan mulai membuat daftar kebutuhan pengguna.

\section{Ideate}

Pada tahap ketiga ini tim perancang melakukan brainstorming bersama untuk mendefinisikan pemrograman ruang pada kantor 24Slides yang didasari dari hasil Analisa. Kemudian dilakukannya pembuatan konsep perancangan dengan membuat moodboard design yang terdiri dari Mikro dan Makro. Pada proses ini tim perancang memberikan ide masing-masing agar didapatkannya solusi terbaik dengan diskusi Bersama.

\section{Prototype}

Setelah didapat konsep desain, tim perancang mulai melakukan pengembangan berupa gambar kerja, detail interior, detail furniture, dan 3D Modelling yang bermaksud untuk memvisualisasikan hasil desain dan skenario penggunaan ruang.

\section{Test}

Hasil desain yang telah dirancang kemudian dilakukan pengujian oleh para dosen mata kuliah Interior Design III, yang kemudian masukan-masukan dari para dosen dapat memberikan evaluasi pada hasil desain ini. Selanjutnya dapat dilakukan perbaikan guna memaksimalkan pada realisasi desain.

\section{HASIL DAN PEMBAHASAN Analisa Eksisting}

Ruang relaksasi pada keadaan existing di 24Slides Indonesia memiliki luas sebesar $25 \mathrm{~m}^{2}$ yang terletak di atas tribun. Pada ruangan tersebut terdapat alat bermain tradisional hingga modern, seperti, congklak, ular tangga, monopoli, dll. Selain menjadi tempat untuk bermain, ruangan ini juga difungsikan sebagai tempat untuk bermain musik, bercengkrama, dan melakukan aktivitas lainnya seperti melukis, atau prakarya lainnya. 


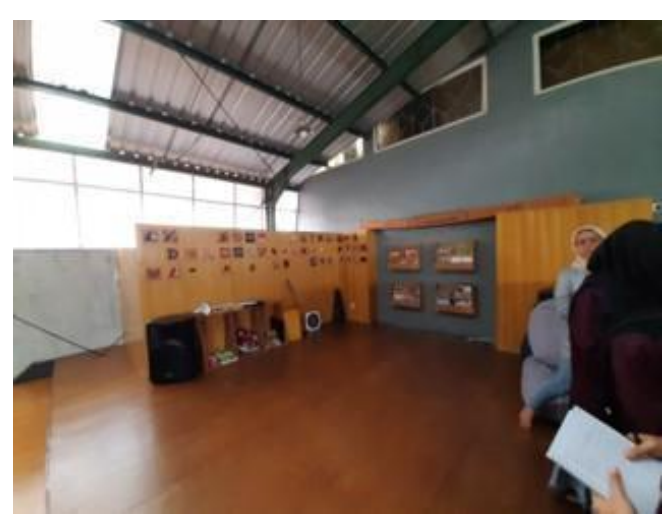

Gambar 1. Ruangan Relaksasi 24Slides Indonesia

Selain melalui survei lapangan, dilakukan juga tahap wawancara terhadap 5 karyawan 24Slides Indonesia sebagai sampel. Melalui proses wawancara, dapat disimpulkan bahwa ruang relaksasi di kantor 24Slides Indonesia menjadi ruangan yang sering ditempati apabila karyawan merasa bosan dengan pekerjaan yang mereka lakukan. Ruangan ini menjadi tempat beristirahat, bermain, dan mencari ide dengan melakukan aktivitas yang mereka suka, seperti bermain, membaca, atau bermain musik. Ruangan ini dinilai efektif dalam meningkatkan kreativitas para karyawan yang sedang bosan dan mempererat antar karyawan melalui kegiatan bonding yang ada. Namun, dari hasil wawancara tersebut, didapatkan beberapa masalah, yaitu:

1. Ruang relaksasi di kantor 24SlidesIndonesia memiliki luas yang sempit sehingga memiliki kapasitas tidak lebih dari 11 orang.

2. Ruang relaksasi yang berbatasan dengan ruang kerja membuat karyawan yang sedang beristirahat tidak dapat bebas beraktivitas dikarenakan akan mengganggu karyawan lain yang bekerja.

3. Konsep dari ruangan relaksasi dinilai kurang membangun suasana fun dikarenakan minimnya fasilitas yang ada dan konsep yang monoton dengan ruang lingkup kerja yaitu urban-industrial.

Selain itu, para karyawan juga mengharapkan bahwa ruang relaksasi ini digunakan untuk bersantai dan bermain tanpa adanya fasilitas wi-fi sehingga mereka dapat beraktivitas dan bersosialisasi dengan lebih dekat satu sama lain.

\section{Konsep Perancangan}

Melalui proses survei lapangan dan wawancara, konsep perancangan desain terhadap ruang relaksasi pada kantor 24Slides Indonesia dibuat untuk memberikan solusi terhadap permasalahan yang ada. Konsep yang diambil sesuai dengan konsep perancangan kantor yaitu fun, youth, dan family-oriented. Sedangkan pemilihan style yang diambil untuk ruangan relaksasi yaitu eclectic, dengan perpaduan urban sebanyak $70 \%$ dan minimalis $30 \%$. Pemilihan urban style didasarkan pada suasana yang ingin dibentuk pada ruang relaksasi ini yaitu suasana homey dan hangat di tengah suasana kota yang padat dan ramai. Pemilihan style minimalis juga didasarkan untuk menciptakan suasana yang rapi, bersih, dan memberikan kelegaan pada karyawan dalam bergerak. Ruangan ini berkonsep open space pada lantai II dengan luas $90 \mathrm{~m}^{2}$ dengan tujuan agar ruangan ini dapat digunakan untuk beragam aktivitas. Ruangan ini menjadi lebih besar $260 \%$ daripada ukuran aslinya sehingga kapasitas ruangan untuk karyawan bertambah. Ruangan relaksasi ini berbatasan langsung dengan 3 ruang yaitu, perpustakaan, office room, dan taman mini dengan dinding yang dipenuhi tanaman rambatan.

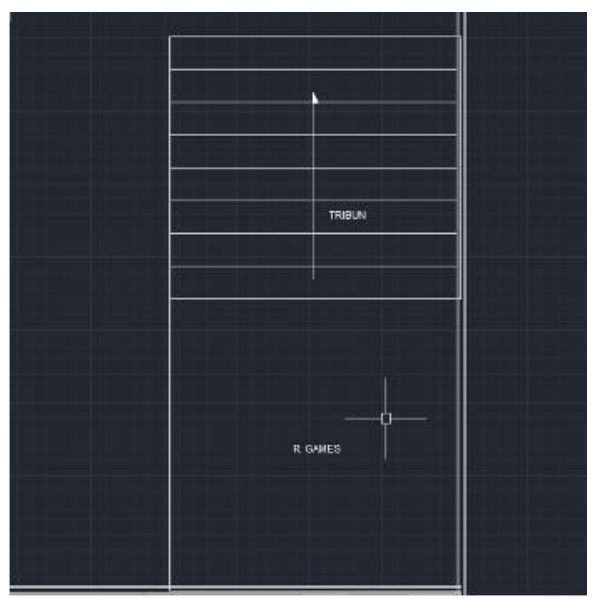

Gambar 2. Denah Existing Ruang Relaksasi 


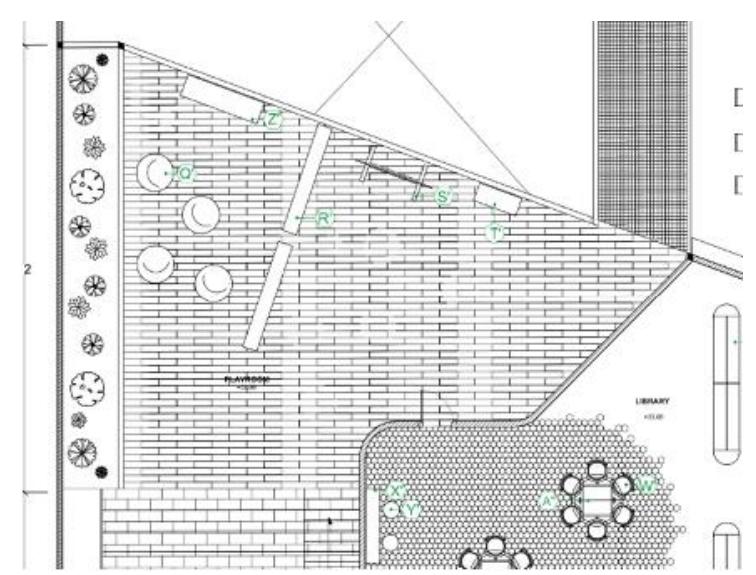

Gambar 3. Denah Perancangan Desain Ruang Relaksasi

Pada ruangan relaksasi, material kayu menjadi material utama dari ruangan ini. Material kayu diterapkan pada bagian lantai, yaitu dengan menggunakan lantai vinyl TACO varian vintage oak. Lantai vinyl ini memiliki tekstur seperti kayu asli dan warna kayu yang mirip seperti aslinya menciptakan suasana yang hangat dalam ruangan.

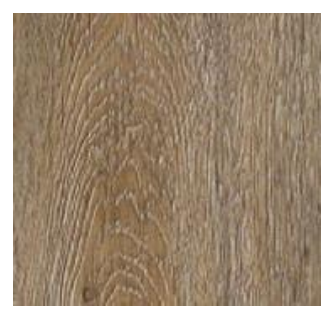

\section{Gambar 4. Lantai Vinyl TACO Vintage Oak [16]}

Pada bagian ruang relaksasi yang berbatasan dengan perpustakaan, diaplikasikan dinding kayu berukuran lebar $10 \mathrm{~cm}$ dengan finishing HPL natural oak. Dinding kayu ini meningkatkan suasana hangat pada ruang relaksasi yang open space ini. Pemilihan dinding kayu ini diharapkan dapat membangun suasana kekeluargaan antar karyawan.

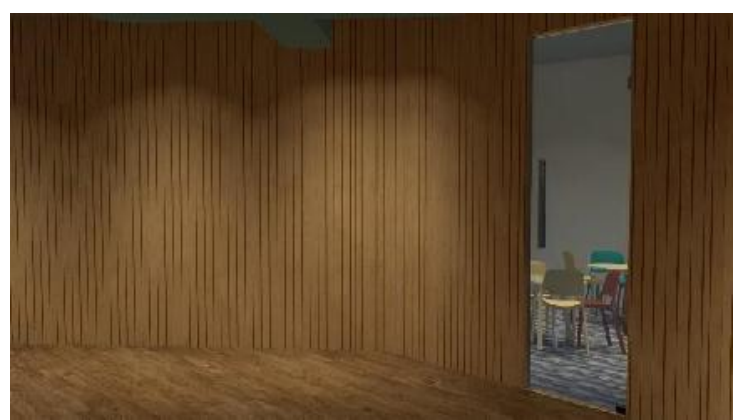

Gambar 5. Perbatasan Ruang Relaksasi dengan Perpustakaan

Material dinding kaca tempered tebal $10 \mathrm{~mm}$ pada sisi ruang yang berdekatan dengan taman mini kantor yang terdapat tanaman rambatnya. Dengan menggunakan kaca tempered yang transparan, karyawan dapat melihat secara langsung tanaman yang merambat dari taman mini kantor tersebut. Pemilihan material kaca yang transparan dipilih agar ketika karyawan sedang bermain atau beristirahat, karyawan dapat melihat tanaman yang merambat pada dinding, sehingga menambah suasana kedekatan dengan alam, dan membuat karyawan lebih rileks dan nyaman. Penggunaan kaca ini juga memaksimalkan pencahayaan alami dari sinar matahari agar masuk ke dalam ruangan relaksasi sehingga ruangan relaksasi juga dapat menghemat energi.

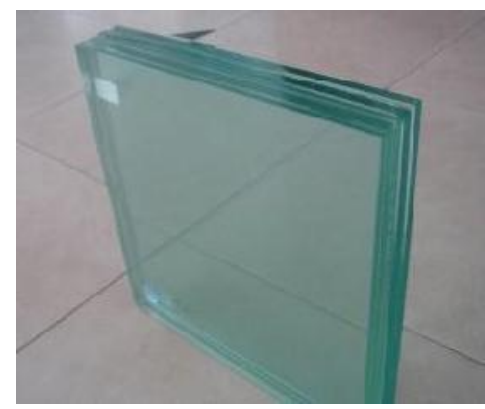

Gambar 6. Kaca Tempered (Suhail, 2016) 


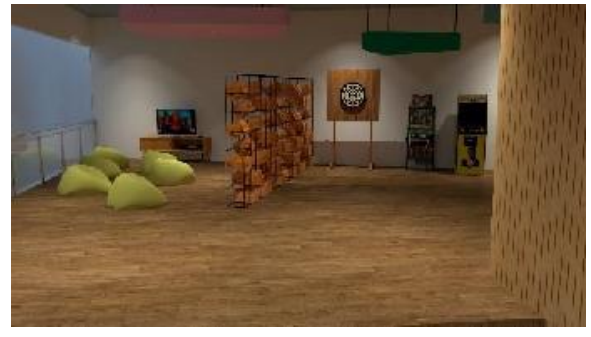

Gambar 7. Perbatasan Ruang Relaksasi dengan Tribun

Untuk bagian ruangangan relaksasi yang berhubungan dengan office room juga menggunakan kaca tempered. Meskipun menggunakan kaca sebagai sekat antar ruangan, jarak antara ruang relaksasi dengan office room tidak langsung berdekatan dikarenakan adanya jarak kosong pada office room lantai II, sehingga suara yang datang dari ruang relaksasi tidak akan masuk sampai ke dalam office room. Dengan penggunaan material kaca ini, juga memberikan kesan luas antar ruang relaksasi dan office room.

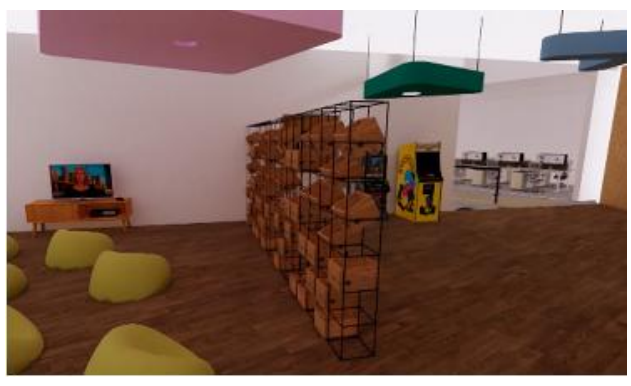

Gambar 8. Perbatasan Ruang Relaksasi dengan office room

Sedangkan untuk pemilihan kursi pada ruangan, penulis memilih bean bag sebagai tempat duduk. Bean bag dipilih karena sifatnya yang lunak dan menyesuaikan dengan orang yang duduk di atasnya. Bean bag menjadi opsi yang tepat agar karyawan dapat bersantai dan beristirahat serta dapat meregangkan tubuhnya ketika sedang merasa bosan, bermain musik, atau ketika mebaca. Material bean bag in sendiri adalah polyester dengan foam pada bagian isi.

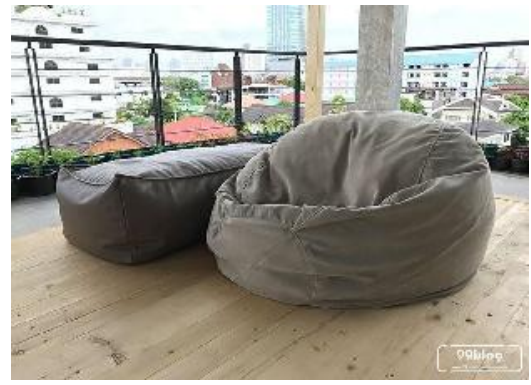

Gambar 9. Bean Bag (Bintang Pinangsia, 2020)

\section{SIMPULAN}

Perancangan ruang relaksasi (funspace) dinilai memiliki peran yang cukup besar bagi karyawan dalam menciptakan kreativitas saat bekerja. Dari analisa yang sudah didapat, penulis membuat ruang relaksasi dengan standar yang dapat mengakomodasi karyawan. Yaitu dengan ruangan yang memiliki suasana hangat, luas, tertata dan memiliki banyak fasilitas untuk menyegarkan pikiran. Maka dari itu, penulis memperluas area ruang relaksasi untuk memperoleh kapasitas yang lebih banyak, kemudian memilih material utama berupa kayu dan menambahkan sekat bermaterial kaca untuk menciptakan suasana yang rileks. Dengan menciptakan desain yang memperhatikan pemilihan material, perabot yang ergonomis, serta penyesuaian terhadap kondisi existing diharapkan menjadi fasilitas yang ideal untuk menunjang produktivitas serta kreativitas para pekerja di kantor 24Slides.

\section{DAFTAR RUJUKAN}

Ali, S.D. "Design Thinking." School of Information System BINUS, December 18, 2017.https://sis.binus.ac.id/2017/12/18/desi gn-thinking-2/. (Diakses pada 12 Juni 2020).

Barsoux JL. (1993). Funny business: Humour, management and business culture. Cassell.

Bolman LG, Deal TE. (2000). Escape from Cluelessness: A Guide for the Organizationally Challenged: an Antidote to Cynicism, Confusion, Corporate Doublespeak, and Other Ailments of Today's Workplace. Amacom. 
Chesbrough, H. (2010). Business model innovation: Opportunities and barriers. Long Range Planning.

Deal TE, Kennedy AA. (1999). The new corporate cultures. New York: Perseus.

Design Desk. "Benefits of introducing fun or play zones in work environments!" March, 31 2017. https://designdesk.in/benefitsintroducing-fun-play-zones-work-

environments/\#: :text=The $\% 20$ office $\% 20 \mathrm{c}$ ulture\%20and\%20ambience,vibes\%20amo ng\%20the\%20office\%20staff. (Diakses pada 12 Juni 2020).

Eisenberger R, Huntington R, Hutchison S, Sowa D. (1986). Perceived organizational support. Journal of Applied Psychology.

Fitriani, Eva. "Wishnutama: Industri Kreatif Jadi Penopang Ekonomi Nasional". 2020, 11Maret.https://investor.id/business/wishn utama-industri-kreatif-jadi-penopangekonomi nasional\#: :text=Sebanyak\%2017\%20subs ektor\%20ekonomi\%20kreatif,tv\%20dan\% 20radio\%2C\%20seni\%20pertunjukkan. (Diakses pada 12 Juni 2020).

Fleming P, Sturdy A. (2009).“Just be yourself!" Towards neo-normative control in organisations?. Employee Relations.

Fluegge ER. (2008). Who put the fun in functional? Fun at work and its effects on job performance. University of Florida.

Howkins, John, (2001). The Creative Economy: How People Make Money from Ideas. The Penguin Press.

Neufert, Peter and Ernst. (2012). Neufert: Architect Data Fourth Edition. WileyBlackWell Publishing.

Patel B, Desai T. (2013). Effect of Workplace Fun on Employee Morale and Performance. International Journal of Scientific Research.

Peters T. (1992). Liberation Management: necessary disorganisation for the nanosecond nineties. Fawcett Colombine.

Pinault L. (2004). The play zone: unlock your creative genius and connect with consumers. Harper Collins.

Suhail. "Sub Sektor Industri Kreatif". Dinas Perindustrian Dan Perdagangan Provinsi Jawa Timur. 2016, 27 Oktober. http://disperindag.jatimprov.go.id/post/de tail?content=sub-sektor-industri-kreatif.

(Diakses pada 12 Juni 2020)

Pinangsia,Bintang. Lantai Vinyl TACO

Vintage Oak.

https://bintangbarupinangsia.com/shop/su plier-distributor-vinyl-murahberkualitas/taco-vinyl-plank/taco-

vintage-oak/. (Diakses pada 12 Juni 2020). 